\title{
Hematoma subungueal
}

\section{Subungual hematoma}

Carolina Palacios-López, ${ }^{1}$ Diana Morales-Olvera ${ }^{2}$

Definición: acumulación de sangre debajo de la uña, del pie o de la mano.

Síntomas: inflamación, dolor y cambio de coloración de la uña a violáceo.

Causa: traumatismo, anticoagulantes, quimioterapia o problemas del sistema inmunológico.

Existe ruptura de vasos capilares del lecho ungueal que provoca extravasación de sangre, en ocasiones la presión ejercida por el hematoma rompe la epidermis y provoca un drenado espontáneo.

\section{Manifestaciones clínicas}

Cuando el traumatismo es obvio y el hematoma no drena, puede causar dolor intenso. En ocasiones, los pacientes no recuerdan haber sufrido traumatismo y solo se observa coloración violácea en la lámina ungueal.

\section{Diagnóstico}

En años recientes el dermatólogo cuenta con la dermatoscopia para confirmar el diagnóstico clínico y guiar el tratamiento de las lesiones ungueales. En caso de duda en el diagnóstico se debe realizar biopsia de uña.

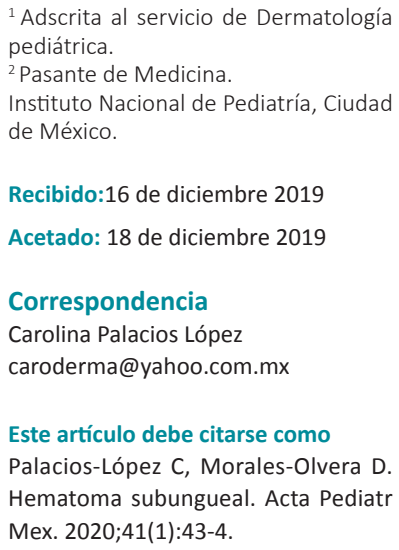




\section{Diagnóstico diferencial}

1. Nevo melanocítico: acumulación de células derivadas de los melanocitos, Ilamadas células névicas.

2. Melanoniquia: acumulación de melanina en la lámina ungueal de distribución longitudinal, por activación focal de los melanocitos (las células implicadas en la producción de melanina) o hiperplasia de estos en la matriz ungueal.

3. Melanoma subungueal: tumor melanocítico maligno, variante del melanoma lentiginoso acral. Se origina en la matriz ungueal y puede iniciar como una melanoniquia; involucra parte del aparato ungueal.

\section{Tratamiento}

Si el paciente llega inmediatamente posterior al traumatismo, lo indicado es drenar el hematoma. Para esto debe realizarse la asepsia y con una aguja de 23" o con la aguja de una jeringa de insulina. Se calienta la punta y se punza en la parte central del hematoma a 45 o $60^{\circ}$. No es necesario aplicar anestesia porque el dolor tan intenso que causa la compresión del hematoma sobre la uña desaparecerá inmediatamente después de puncionarla y de que drene la sangre. Figuras 1,2 y 3 .

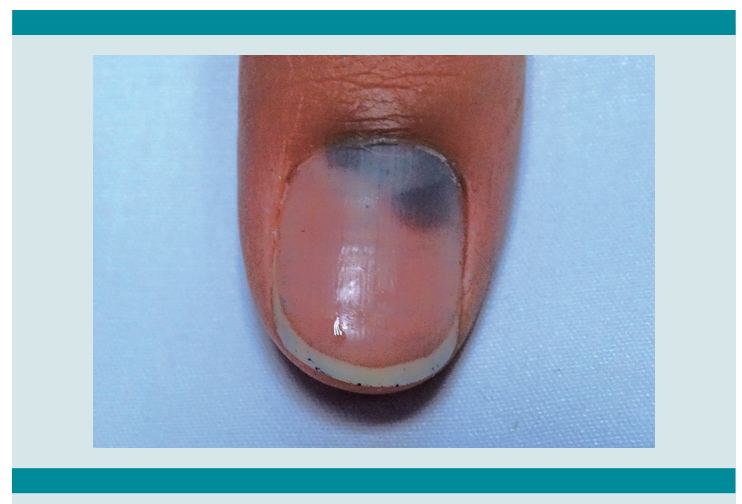

Figura 1. Hematoma subungueal por aplastamiento del dedo con una puerta.

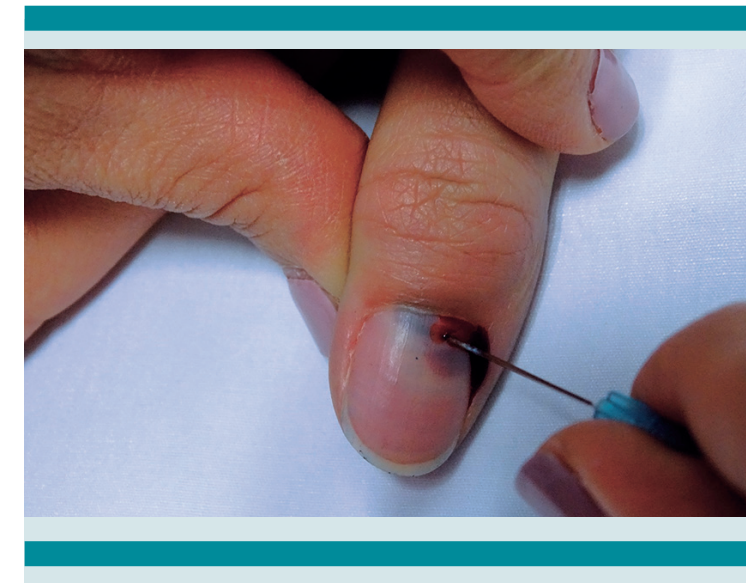

Figura 2. Punción del hematoma y salida de sangre.

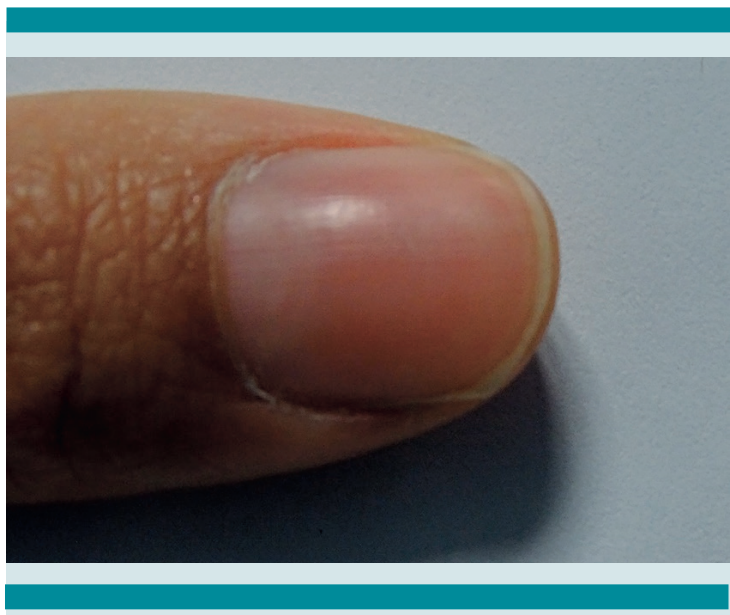

Figura 3. Resolución en 6 meses.

\section{LECTURAS RECOMENDADAS}

1. Faster R, Bothner J. Subungual hematoma Update Nov. 2019:1-24. https://www.ncbi.nlm.nih.gov/books/ NBK482508/

2. Piraccini BM, et al. Onychoscopy: Dermoscopy of the nails. Dermatol Clin. 2018; 36 (4):431-38

3. Deinlein $\mathrm{T}$, et al. Acral melanoma mimicking subungueal hematoma. Graz, Austrias. doi.org/10.1016/j.det.2018.05.010

4. Mun JH, et al. Dermoscopy of sunbungual haemorrhage: its usefulness in differential diagnosis from nail-unit melanoma. British Journal of Dermatology. 2013; 168: 1224-29. https:// doi.org/10.1111/bjd.12209

5. Tzeng YS., Use of an 18-gauge needle to evacuate subungual hematomas. J Emerg Med. 2013; 44 (1): 196-7. https://doi. org/10.1016/j.jemermed.2012.05.009 